\title{
The donkey's shadow
}

\author{
Joanna Chikwe, MD, ${ }^{a, b}$ and David H. Adams, MD
}

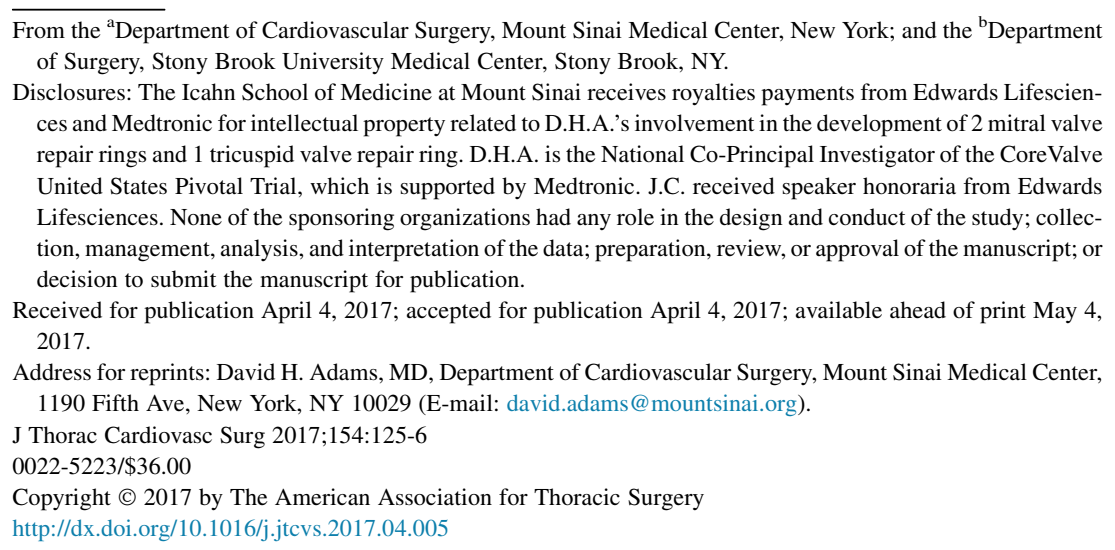

Tirone David is right. He is right because no retrospective study, let alone a clinical trial, will show that concomitant tricuspid annuloplasty for moderate tricuspid regurgitation during degenerative mitral repair reduces mortality or even freedom from reoperation for tricuspid regurgitation. This is primarily because death, severe tricuspid regurgitation, and tricuspid reoperation in this population are rare end points. With these end points, Dr David ${ }^{1}$ rightly argues in this issue of the Journal, his retrospective data show no benefit for an aggressive approach to performing tricuspid annuloplasty for annular dilatation. It is an effective argument, as arguments go.

Aesop tells a fable about arguing. On a hot day, so the story goes, two travelers argued over who should rest in the shadow of the donkey they had been riding. While they were arguing, the donkey ran off, leaving the travelers with neither shade nor a ride. The moral of this tale is that in quarreling about a shadow, we lose sight of what matters.

Actually, what matters is that in real-world practice today, there is still enormous variation among institutions and surgeons in the performance and quality of reconstructive valve surgery. 2,3 A significant number of patients with degenerative mitral regurgitation and repairable heart valves still receive a valve replacement. ${ }^{2}$ Few, if any, surgeons practicing today equal Dr David's expertise and accomplishments in valve reconstruction. His experience reported here replicates our benchmark for mitral surgery, ${ }^{4}$ and we must ensure that all our patients have access to care of this quality.

It also matters that there is more agreement than disagreement as to which patients will benefit from concomitant tricuspid repair. We should not lose sight of this consensus. In the discussion of Dr David's article after its presentation at the annual meeting of the American Association for Thoracic Surgery, transcribed in this issue of the Journal, he was asked, "If you operate tomorrow on a 65-year-old patient with severe mitral regurgitation, mild tricuspid point. $^{6}$

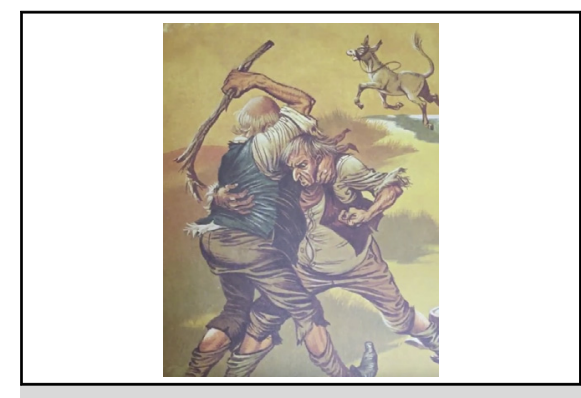

Debating nuances obscures the key issues: We agree more than we differ in tricuspid repair.

\section{Central Message}

We are all repairing more functional tricuspid regurgitation at the time of mitral surgery.

See Article page 110.

regurgitation, right ventricular dilatation, moderate pulmonary hypertension, and ejection fraction of $55 \%$, and their tricuspid diameter is $45 \mathrm{~mm}$, are they going to get an operation? Are they going to get a tricuspid repair with mitral repair?" Dr David replied, "Absolutely. Yes they are. They should have tricuspid annuloplasty." "We agree on the fundamental concept that patients with mild or even no tricuspid regurgitation who have other risk factors for progression of tricuspid disease will likely benefit from concomitant tricuspid annuloplasty.

This analysis of Dr David's experience does not provide data to determine this, however; the end points that he has chosen are clinically important and understandable given the historic nature of this cohort, but they don't tell the whole story. With much more granular echocardiographic data from contemporary practice, our group showed that moderate tricuspid regurgitation, right ventricular dysfunction, and pulmonary hypertension after degenerative mitral repair could be reduced safely and effectively by targeting an aggressive strategy of tricuspid annuloplasty toward sicker patients with worse right-sided parameters-with the results that these values improved with time to match those of younger, fitter patients with minimal tricuspid dilatation or regurgitation and normal right ventricular function..$^{5}$ Importantly, tricuspid regurgitation was almost completely eliminated. Of course, you can also mimic the elimination of tricuspid regurgitation after isolated mitral surgery by ignoring patients on diuretic therapy or with ventricular dysfunction and limiting median echocardiographic follow-up to 2 years, but that is beside the 
The true impact, however, of neglecting the tricuspid valve is the $33 \%$ incidence of moderate or severe tricuspid regurgitation 5 years after degenerative mitral repair reported by Yilmaz and colleagues ${ }^{7}$ in their supplemental data. That seems to us to be suboptimal, but however suboptimal it may be, it does not compare to the negative impact of delayed intervention and unnecessary mitral valve replacements in contemporary practice. Addressing this issue first and foremost deserves our undivided attention and effort. As far as concomitant tricuspid repair goes, Mount Sinai and Toronto share many more similarities than differences in our current approach (again, read the discussion that followed the presentation of the article $\left.^{1}\right)$. We predict that our tricuspid repair rates are converging-we are becoming more conservative, while Dr David is clearly becoming more aggressive. Arguing about the $10 \%$ to $20 \%$ difference risks losing sight of the fact that we agree on how to manage most of our patients.

Aesop was right about the donkey.

\section{References}

1. David TE, David CM, Fan CS, Manlhiot C. Tricuspid regurgitation is uncommon after mitral valve repair for degenerative disease. J Thorac Cardiovasc Surg. 2017; 154:110-22.e1.

2. Chikwe J, Toyoda N, Anyanwu A, Itagaki S, Egorova N, Boateng P, et al. Relation of mitral surgery volume to repair rate, durability and survival. J Am Coll Cardiol. 2017 [In press].

3. Bolling SF, Li S, O'Brien SM, Brennan JM, Prager RL, Gammie JS. Predictors of mitral valve repair: clinical and surgeon factors. Ann Thorac Surg. 2010;90: 1904-11; discussion 1912.

4. Castillo J, Anyanwu A, Fuster V, Adams DH. A near 100\% repair rate for mitral valve prolapse is achievable in a reference center: implications for future guidelines. J Thorac Cardiovasc Surg. 2012;144:308-12.

5. Chikwe J, Itagaki S, Anyanwu A, Adams DH. Impact of concomitant tricuspid annuloplasty on tricuspid regurgitation, right ventricular function and pulmonary artery hypertension after repair of mitral valve prolapse. J Am Coll Cardiol. 2015;65: 1931-8.

6. Sordelli C, Lancellotti P, Carlomagno G, Di Giannuario G, Alati E, De Bonis M, et al. Tricuspid annular size and regurgitation progression after surgical repair for degenerative mitral regurgitation. Am J Cardiol. 2016;118:424-31.

7. Yilmaz O, Suri RM, Dearani JA, Sundt TM III, Daly RC, Burkhart HM, et al. Functional tricuspid regurgitation at the time of mitral repair for degenerative leaflet prolapse: the case for a selective approach. J Thorac Cardiovasc Surg. 2011;142:608-13. 